\section{Direct Observation of GFP Gene Expression Transduced with HSV- 1/EBV Amplicon Vector in Unfixed Tumor Tissue}

BioTechniques 28:206-208 (February 2000)

Green fluorescent protein (GFP) has been widely used as a live reporter gene in cells both in vitro and in vivo $(1,4,8-10,12-14)$. Herpes simplex virus type-1 (HSV-1) amplicon vector has been used for gene transfer into tumor and normal quiescent neural cells in vivo and successful gene expression has been achieved $(2,3,5-7,11,15)$. However, we and others have attempted but failed to directly observe GFP gene expression after direct injection of GFP amplicon viral vector supernatant into rat brain. Therefore, we used an antiGFP immunohistochemical technique to identify positive GFP expression cells in paraformaldehyde-fixed brain tissue (unpublished data).

We report here a method to directly observe GFP expression in unfixed, human melanoma tumor xenografts injected subcutaneously into athymic nude mice. We used our novel chimeric HSV/EBV amplicon vector (pHE700) to carry a humanized GFP gene (16). The pHE700 vector contains a replication origin (oriS) and a packaging signal from HSV-1 so that the vector can replicate and be packaged into HSV-1 with the help of the replication-defective $\mathrm{HSV}-1$ ( $\mathrm{Cgal} \Delta 3$, in this experiment). The vector also contains a latent replication origin (oriP) and an Epstein-Barr virus nuclear antigen 1 (EBNA-1) element from Epstein-Barr virus (EBV) so that the vector can be maintained as an episomal form in the transduced cells. The vector retains HSV-1 neurotropism and a wide range of host cell infectivity (16). The GFP gene was inserted into the multiple cloning site of pHE700 driven by a human cytomegalovirus immediate-early promoter (CMV) to make a pHE700GFP vector. The amplicon was packaged in a rolling-cycle replication model so that the packaged pHE700-GFP viral vector contains about 13 copies of the GFP gene. Multiple copies of the transgene in the amplicon vector make it suitable for high level transgene expression experiments.

The experiment was performed on 24 adult nude mice divided into 2 groups. A subcutaneous human tumor xenotransplant was generated by injecting $5 \times 10^{6} \mathrm{~A} 375$ human melanoma cells in $50 \mu \mathrm{L}$ into the anterior abdominal wall. When the tumor reached approximately $4 \mathrm{~mm}$ in diameter (usually within 5 days after injection), $100 \mu \mathrm{L}$ of pHE700-GFP vector stock solution (amplicon titer: $1 \times 10^{7} \mathrm{gfu} / \mathrm{mL}$, gfu: green forming units) was injected (Day 1) into each tumor of 12 mice. Then, $100 \mu \mathrm{L}$ of Hanks' Balanced Salt Solution (HBSS) was injected into the control animals' tumors. All animals were cared for under an approved animal protocol using AAALAC guidelines.

On days 3, 7 and 14, four animals were euthanized with $\mathrm{CO}_{2}$ after vector injection. Tumor samples were harvested immediately without fixation and frozen at $-20^{\circ} \mathrm{C}$. After serial cryostat sectioning, frozen sections (10-20 $\mu \mathrm{m}$ thick) were mounted on glass slides and observed immediately under a fluorescent microscope and photographed. The sections were then fixed with $4 \%$ paraformaldehyde in $1 \times$ PBS (pH 7.2) for 10-30 min and were first processed for GFP immunohistochemistry and then with $\beta$-galactosidase ( $\beta$ gal) histochemistry to identify expression of LacZ gene of HSV-1, as previously described (16).

For immunohistochemistry of GFP, the sections were incubated with $0.3 \%$ Triton ${ }^{\circledR} \mathrm{X}-100$ in $1 \times \mathrm{PBS}$ for $30 \mathrm{~min}$ at room temperature, then blocked with

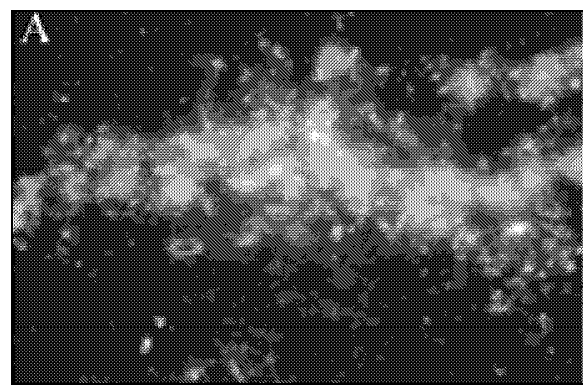

Figure 1. GFP gene expression in xenotransplant subcutaneous melanoma tumors in nude mice. GFP was co-localized with fluorescent microscopy and immunohistochemistry two days after tumor injection of pHE700-GFP supernatant. Two photos were taken from the same region of one section. (A) GFP fluorescence in an unfixed frozen section, 200×; (B) positive GFP immunoreactive structures (violet color) and positive $\beta$-gal staining (blue structures) in the same but fixed section, $200 \times$.

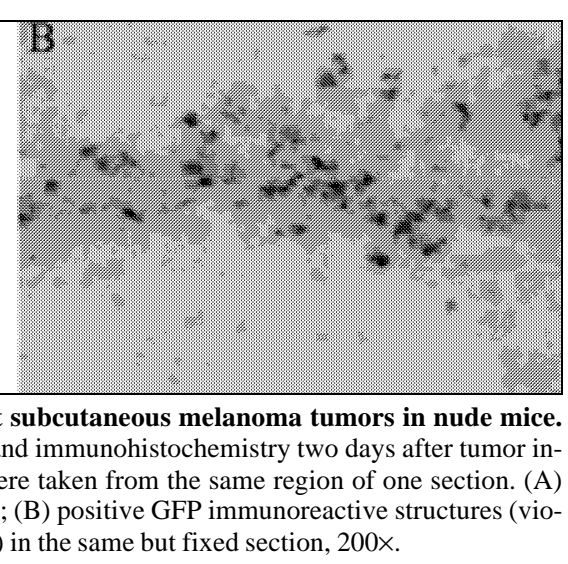

$1 \%$ BSA and $10 \%$ normal goat serum in $1 \times$ PBS for $1 \mathrm{~h}$ at room temperature. The sections were next incubated with anti-GFP primary antibody raised in rabbit (1:500, Santa Cruz Biotechnology, Santa Cruz, CA, USA) at room temperature for $2 \mathrm{~h}$ and $4^{\circ} \mathrm{C}$ overnight, and secondary antibody raised in goat and conjugated with alkaline phosphatase (1:100, Sigma, St. Louis, MO, USA) at room temperature for $2 \mathrm{~h}$. The third incubation was performed in BCIP/NBT substrate solution (Sigma) at room temperature for 5-10 min. Several washes with $1 \times$ PBS were done at the intervals between and after incubations.

Two days after tumor injection of pHE700-GFP supernatant, GFP fluorescence was observed in multiple areas of the tumor (Figure 1A). On the same sections, the GFP fluorescence was confirmed by GFP immunoreactivity (Figure 1B), and $\beta$-gal (delivered by Cgal $\Delta 3$ helper virus) positive cells were found distributed in the same area as GFP fluorescence (Figure 1B). Six days after injection, GFP fluorescence, GFP immunoreactivity and $\beta$-gal positive staining were still observed but less than that noted on the samples two days after injection. Thirteen days after injection, no GFP gene and $L a c Z$ gene expressions were observed. No sections of control tumor injected with HBSS demonstrated GFP fluorescence.

It has been established that the HSV1 vector is suitable for infection of post-mitotic cells and especially for nerve cells because of its affinity for neurons (2). In the present study, we observed GFP fluorescence in unfixed tumor tissue collected two and six days after vector injection into subcutaneous 
human xenograft tumors. This GFP expression was identified further with immunohistochemistry. We found GFP fluorescence was distributed more widely than GFP immunoreactivity. This indicates that fluorescent microscopy is more sensitive than immunohistochemistry in detecting GFP expression. Gene transfer into the xenotransplanted tumor model by our HSV-1/EBV amplicon vector was quite high (Reference 17 and S. Wang, unpublished data). In this investigation, we injected a total of $1 \times 10^{6}$ of pHE700-GFP amplicon vector into a tumor that was approximately $4 \mathrm{~mm}$ in diameter. Two days after injection, GFP expression was found in about $80 \%$ of the tumor sections. The number of the GFP positive cells increased from the edge of the tumor towards the center.

Interestingly, we found that the sec- tions had to be observed by fluorescent microscopy within approximately 5 min of sectioning at room temperature. After $5 \mathrm{~min}$, no GFP fluorescence could be observed in the same section. In addition, the GFP fluorescence reappeared in the same section if it was frozen again to $-20^{\circ} \mathrm{C}$. After applying a coverslip with PBS as a mounting medium, we detected no GFP fluorescence. These data suggest that direct observation of GFP expression by fluorescent microscopy in unfixed tissue is simple and saves time, but the microscopy must be performed within 5 min after cryostat sectioning.

\section{REFERENCES}

1.Aboody-Guterman, K.S., P.A. Pechan, N.G. Rainov, M. Sena-Esteves, A. Jacobs, E.Y. Snyder, P. Wild, E. Schraner et al. 1997. Green fluorescent protein as a reporter for retrovirus and helper virus-free HSV-1 amplicon vector-mediated gene transfer into neuronal cells in culture and in vivo. Neuroreport 8:3801-3808

2.Battleman, D.S., A.I. Geller and M.V. Chao. 1993. HSV-1 vector mediated gene transfer of the human nerve growth factor receptor p75hNGFR defines high affinity NGF binding. J. Neurosci. 13:941-951.

3.Bergold, P.J., P. Casaccia-Bonnefil, Z. XiuLiu and H.J. Federoff. 1993. Transsynaptic neuronal loss induced in hippocampal slice cultures by a herpes simplex virus vector expressing the GluR6 subunit of the kainate receptor. Proc. Natl. Acad. Sci. USA 90:6165-6169.

4.de Martin, R., M. Raidl, E. Hofer and B.R. Binder. 1997. Adenovirus-mediated expression of green fluorescent protein. Gene Ther. 4:493-495.

5.During, M.J., J. Naegele, K. O'Malley and A.I. Geller. 1994. Long-term behavioral recovery in Parkinsonian rats by an HSV-1 vector expressing tyrosine hydroxylase. Science 266:1399-1403.

6.Federoff, H.J., M.D. Geschwind, A.I. Geller and J.A. Kessler. 1992. Expression of NGF in vivo, from a defective HSV-1 vector, prevents effects of axotomy on sympathetic neurons. Proc. Natl. Acad. Sci. USA 89:1636-1640.

7.Ho, D.Y., E.S. Mocarski and R.M. Sapolsky. 1993. Altering central nervous system physiology with a detective HSV-1 vector expressing the glucose transporter gene. Proc. Natl. Acad. Sci. USA 90:3655-3659.

8.Kafri, T., U. Blomer, D.A. Peterson, F.H. Gage and I.M. Verma. 1997. Sustained expression of genes delivered directly into liver and muscle by lentiviral vectors. Nat. Genet. 17:314-317.

9.Kain, S.R., M. Adams, A. Kondepudi, T.-T. Yang, W.W. Ward and P. Kitts. 1995. Green fluorescent protein as a reporter of gene expression and protein localization. BioTechniques 19:650-655.
10.Kandel, E.S., B.-D. Chang, B. Schott, A.A. Shtil, A.V. Gudkov and I.B. Roninson. 1997. Applications of green fluorescent protein as a marker of retroviral vectors. Somat. Cell. Mol. Genet. 23:325-340.

11.Lawrence, M.S., D.Y. Ho, G.H. Sun, G.K. Steinberg and R.M. Sapolsky. 1996. Overexpression of Bcl-2 with herpes simplex virus vectors protects CNS neurons against neurological insults in vitro and in vivo. J. Neurosci. 16:486-496.

12.Levy, J.P., R.R. Muldoon, S. Zolotukhin and C.J. Link. 1996. Retroviral transfer and expression of a humanized, red-shifted green fluorescent protein gene into human tumor cells. Nat. Biotechnol. 14:610-614.

13.Moore, A., E. Marecos, M. Simonova, R. Weissleder and A. Bogdanov, Jr. 1998. Novel gliosarcoma cell line expressing green fluorescent protein: A model for quantitative assessment of angiogenesis. Microvasc. Res. 56:145153.

14.Peel, A.L., S. Zolotukhin, G.W. Schrimsher, N. Muzyczka and P.J. Reier. 1997. Efficient transduction of green fluorescent protein in spinal cord neurons using adeno-associated virus vectors containing cell type-specific promotors. Gene Ther. 4:16-24.

15.Rainov, N.G., M. Sena-Esteves, C. Fraefel, K.U. Dobberstein, E.A. Chiocca and X.O. Breakefield. 1998. A chimeric fusion protein of cytochrome CYP4B1 and green fluorescent protein for detection of pro-drug activating gene delivery and for gene therapy in malignant glioma. Adv. Exp. Med. Biol. 451:393403.

16.Wang, S., S. Di, W.-B. Young, C. Jacobson and C.J. Link. 1997. A novel herpes virus amplicon system for in vivo gene delivery. Gene Ther. 4:1132-1141.

17.Wang, S. and J.M. Vos. 1996. A hybrid herpesvirus infectious vector based on EpsteinBarr virus and herpes simplex virus type 1 for gene transfer into human cells in vitro and in vivo. J. Virol. 70:8422-8430.

Address correspondence to Dr. Suming Wang, Human Gene Therapy Research Institute, 1415 Woodland Avenue, Suite 218, Des Moines, Iowa 50309, USA. Internet: wangsm@ihs.org

Received 2 April 1999; accepted 2 November 1999.

Jianguo Qi, Charles J. Link, Jr. and Suming Wang Human Gene Therapy Research Institute

John Stoddard Cancer Center Des Moines, IA, USA 